OPEN ACCESS

Edited by:

Hui Zhang,

Institute of Oceanology (CAS), China

Reviewed by:

Ming Liu,

Morgan State University,

United States

Fang Wang,

Ocean University of China, China

*Correspondence:

Jinghui Fang

hui861@163.com

Zengjie Jiang

jiangzj@ysfriac.cn

Specialty section:

This article was submitted to

Marine Biology,

a section of the journal

Frontiers in Marine Science

Received: 20 April 2021

Accepted: 19 May 2021

Published: 11 June 2021

Citation:

Fang J, He W, Meng S, Jiang Z,

Fang J, Mao Y and Liang B (2021)

The Sediment Selectivity of Perinereis

aibuhitensis Larvae: Active or

Passive? Front. Mar. Sci. 8:697736.

doi: 10.3389/fmars.2021.697736

\section{The Sediment Selectivity of Perinereis aibuhitensis Larvae: Active or Passive?}

\author{
Jinghui Fang1,2*, Wei He ${ }^{1,2}$, Shan Meng ${ }^{1,2,3}$, Zengjie Jiang ${ }^{1,2 *}$, Jianguang Fang ${ }^{1}$, \\ Yuze Mao ${ }^{1,2}$ and Bo Liang ${ }^{1,2}$
}

\begin{abstract}
${ }^{1}$ Laboratory for Marine Fisheries Science and Food Production Processes, Yellow Sea Fisheries Research Institute, Chinese Academy of Fishery Sciences, Qingdao, China, ${ }^{2}$ College of Fishers and Life Science, Shanghai Ocean University, Shanghai, China, ${ }^{3}$ China Ocean Press, Beijing, China
\end{abstract}

The selectivity of Perinereis aibuhitensis larvae on different sediment types was studied using an experimental behavioral device in the lab. There were six types of sediment with different organic matter content: $2.19,2.30,2.86,3.25,3.51$, and 5.52\%. The results indicated significant differences in the six treatments' organic matter content $(p<0.05)$. When the $P$. aibuhitensis larvae initially attached to the sediment, the larvae's density showed no significant difference among the six treatments. The density of larvae decreased gradually during the experimental period. It increased with the increasing organic matter content in sediment at every sampling time, but there was no significant difference $(p>0.05)$. The larvae's specific growth rate in the first month was significantly higher than those in the second and third months $(p<0.05)$. The mortality showed no significance at different sediments in equal sampling times, but the mortality was lower in high organic matter content sediments. This study showed that the $P$. aibuhitensis larvae did not make an active selection; random selection happened when initially attached to the sediment with different organic matter contents. Higher organic matter content in the sediment was more conducive to larvae survival, and the organic matter content is the limitation factor on the mortality and the density. The different densities in the natural habitat of $P$. aibuhitensis might occur due to the passive selection by the environment.

Keywords: Perinereis aibuhitensis, selectivity, behavior, organic matter, density, specific growth rate

\section{INTRODUCTION}

Polychaeta, one of the most typical taxon of benthic communities, is a common infauna of the coastal intertidal zone involved in the reworking of sediment and ecological recovery in natural waters (Heilskov and Holmer, 2001; Koo and Seo, 2017; Chouikh et al., 2020; Gopal et al., 2020). The bioturbation behaviors of polychaetes within the sediment include feeding, burrowing, and moving, which promote nutrients exchange and oxygen flux at the sediment-water surface resulting in accelerated mineralization and decomposition of the sediment's organic matter (Duport et al., 2006, 2007). The density and biomass of polychaetes influence environmental recovery efficiency induced by bioturbation (Duport et al., 2006; Hu et al., 2020).

Polychaetes biomass distribution differs by habitat location and tidal zones. According to the studies of Hylleberg (1975), Kihslinger and Woodin (2000), and Fang et al. (2018), polychaetes 
prefer sediment with higher organic content. This tendency probably gives rise to the difference in biomass distribution. However, Meng et al. (2020) found that Perinereis aibuhitensis exhibited a slight (not significant) selectivity for different natural sediment types, probably due to their hydrogen sulfide content. Compared with adult polychaetes, larvae are more sensitive to environmental changes. A specific sediment preference possibly caused the distributions of adult polychaetes during the larval stage. Shi and Zhao (1993) found that sediment quality influences the growth and survival rate of $P$. aibuhitensis larvae. A mixture consisting of mud and sand was more conducive to the larvae's growth and survival. In the polychaetes natural habitat, how the different distributions happened in a similar environment? Thus, to elucidate sediment selectivity of polychaete larvae is required. Here whether the larvae preferred sediment when they are attached (initiative) or if they could be selected by the environmental conditions after attachment (passive) is examined.

P. aibuhitensis (Grube, 1878), a common polychaete in intertidal and estuarine zones (Sun and Yang, 2004), has a high tolerance to polluted environments (Li et al., 2017) and a significant impact on bioturbation (Koo and Seo, 2017). In a previous study, we found that environmental parameters, such as organic matter and hydrogen sulfide at different tidal zones of the natural habitat of $P$. aibuhitensis were significantly different (Fang et al., 2017). The biomass distribution was also different among tidal zones. Here, the distribution of $P$. aibuhitensis larvae based on the substrate's organic matter composition was evaluated after attachment to the sediment. Moreover, the survival and growth rates of the larvae in different substrates were determined. The work presented here will provide helpful information on the impacts of sediment's organic matter content on the attachment and survival of $P$. aibuhitensis larvae, which could explain polychaetes distribution in sediments.

\section{MATERIALS AND METHODS}

\section{Hatching $P$. aibuhitensis Larvae}

A $100 \mathrm{~L}$ sterilized vat with filtered seawater was prepared for insemination. The water temperature was adjusted to $20 \pm 1^{\circ} \mathrm{C}$. Slight and continuous aeration was provided. The parental $P$. aibuhitensis obtained from a polychaete farm in Rushan, Weihai (female $3.7 \pm 0.2 \mathrm{~g}$; male $3.5 \pm 0.2 \mathrm{~g}$ ) were put into the vat naturally spawn. Four hours after spawning and the parents were removed.

The larvae's development was observed once a day under an anatomical lens (Olympus, SZ51-SET). After 7-10 days, when the nectochaeta larvae with four chaetigerous segments accounted for more than $80 \%$ of the total larvae, the water was stirred evenly and divided into three experimental devices (Figure 1) to a final density of $1.5 \mathrm{ind} . / \mathrm{mL}$. During this stage, there was no other food provided.

\section{Preparation of Sediments}

The sediments used in the experiment were collected from the intertidal zone of the natural habitat of $P$. aibuhitensis. Sediments were air-dried and crushed for use. Kelp powder and commercial shrimp feed were mixed at a 9:1 weight ratio. The mixed powder was added to the crushed sediments to make experimental sediments according to the weight proportion of 0 , $1,2,4,6$, and $12 \%$, which are numbered as $1 \#, 2 \#, 3 \#, 4 \#, 5 \#$, and 6\#. The experimental sediments were placed in individual experimental devices in the order of proportions and soaked in seawater with continuous aeration to make them naturally settle. Sediments were allowed to stabilize for 3 weeks, with daily seawater replacement. The sediment depth after sedimentation was about $20 \mathrm{~cm}$.

\section{Experimental Management and Data Measurement}

At the four chaetigerous segments stage, nectochaeta larvae were laced into the experimental device and fed with the appropriate amount of Chlorella spp (1,000-2,000 cell $/ \mathrm{ml})$. The density of larvae in the water was monitored daily, and the initial number of $P$. aibuhitensis in the sediment was determined when there were no planktonic larvae in the water. Before density determination, the seawater in the device was slowly siphoned out without disturbing the sediment, and then two $2 \mathrm{~cm} \times 5 \mathrm{~cm}$ and two $3 \mathrm{~cm} \times 5 \mathrm{~cm}$ hard plastic plates were inserted into the sediment to form a cuboid with $2 \mathrm{~cm} \times 3 \mathrm{~cm} \times 5 \mathrm{~cm}$ in width, length, and height. A total of three samples were monitored monthly. All the sediment in the cuboid was removed and placed into a $200 \mathrm{~mL}$ glass beaker. The seawater was added into the beaker and gently mixed the seawater and sediment to be muddy water. The end of the plastic eyedropper was cut off to draw the sediment from the beaker slowly. The muddy water was then placed in a petri dish and gently shaken so that it would be evenly spread over the petri dish. The point is that the spread muddy water must be semitransparent. The larvae in the petri dish were observed under an anatomical lens, and the number and size of the larvae were determined. The size was assessed by the number of segments in the larvae. The procedure was repeated until all the sediment in the beaker was observed. The observation was performed monthly. To ensure the $P$. aibuhitensis density measures' accuracy, the partitions were used to separate the vacant part from other sediments after taking the sediment samples.

\section{Determination of Organic Matter}

Sediment samples from different depths (surface layer: 0-0.5 cm; deep layer: about $5 \mathrm{~cm}$ ) were dried in an oven (DHG-9240A, Shanghai) at $70^{\circ} \mathrm{C}$ for $72 \mathrm{~h}$ to a constant weight. The dried samples were ground with a grinder. About $1.0 \mathrm{~g}$ of the sediment was placed in a crucible and calcined in a muffle furnace (SX3-4$10 \mathrm{X}$, Yantai) at $450^{\circ} \mathrm{C}$ for $6 \mathrm{~h}$ to determine the content of organic matter in the sediment.

\section{Larvae Density and Mortality}

The density of larvae in the sediment was determined every month. The number of larvae per unit area was recorded as density.

$$
D=\frac{\mathrm{n}}{\mathrm{S}}
$$



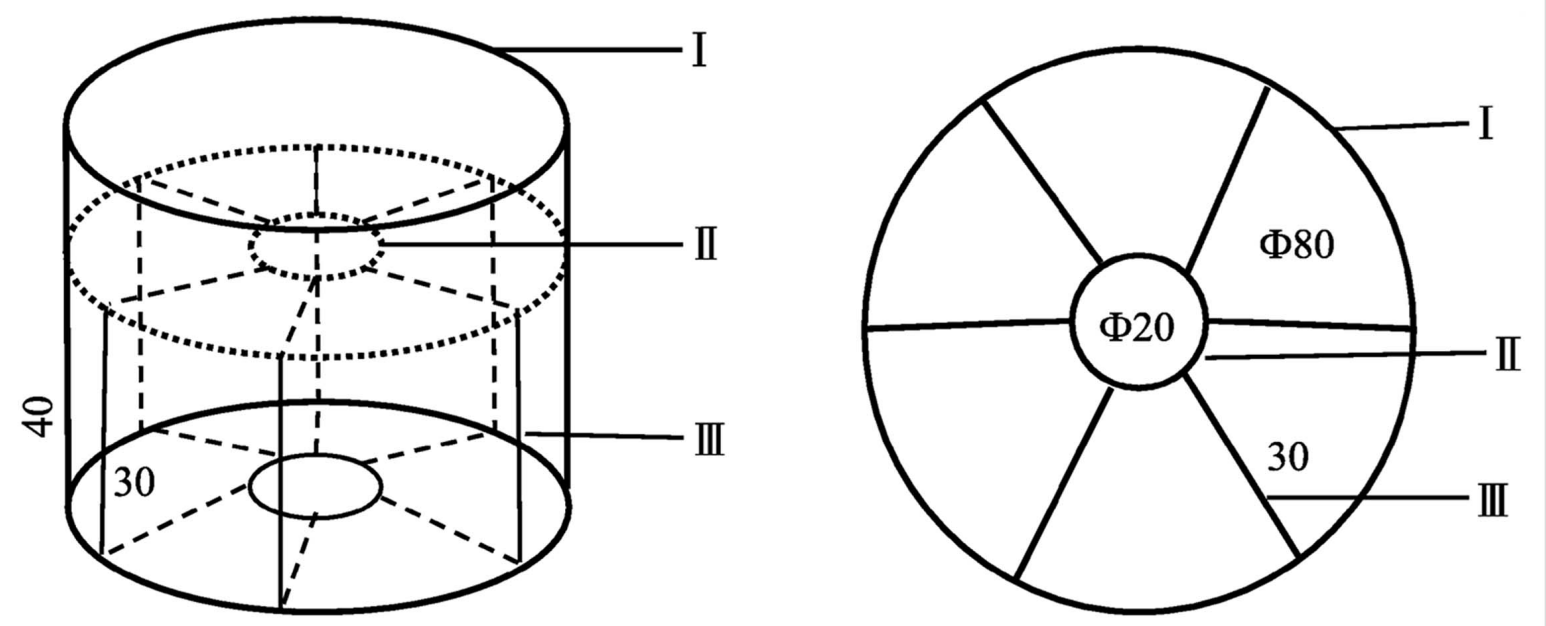

FIGURE 1 | Experimental device for selection behavior of $P$. aibuhitensis larvae. The device is a cylindrical container with a diameter of $80 \mathrm{~cm}$ and a height of $40 \mathrm{~cm}$. Part I is the uppermost outer edge of the device. Part I's center is cylindrical, with a $20 \mathrm{~cm}$ diameter, a $30 \mathrm{~cm}$ height, and a slightly sunken disk-shaped structure on the top. Part III is a square partition with a side length of $30 \mathrm{~cm}$, which evenly divides the space around part II into six parts.

Where $\mathrm{D}\left(\mathrm{ind} / \mathrm{cm}^{2}\right.$ ) is the larvae density, $\mathrm{n}$ (ind) is the number of larvae, and $\mathrm{S}\left(\mathrm{cm}^{2}\right)$ is the sampling area.

The mortality was calculated using the ratio of the density measured at the sampling time to the density measured at the previous sampling time.

$$
M=\left(1-\left(\frac{D_{n}}{D_{n-1}}\right)\right) \times 100 \%
$$

Where $\mathrm{M}(\%)$ is the mortality, $\mathrm{D}_{\mathrm{n}}\left(\mathrm{ind} / \mathrm{cm}^{2}\right)$ is the density of the $\mathrm{n}^{\text {th }}$ month, and $\mathrm{D}_{\mathrm{n}-1}\left(\mathrm{ind} / \mathrm{cm}^{2}\right)$ is the density of the ( $\mathrm{n}$ $1)^{\text {th }}$ month.

\section{Specific Growth Rate}

The specific growth rate (SGR) of the larvae was measured monthly. The SGR was calculated based on the number of larva segments recorded at each sampling.

$$
\bar{S}=\frac{s 1+s 2+s 3+\cdots+s m}{m}
$$

Where $\bar{S}$ is the average number of segments, $m$ is the number of $P$. aibuhitensis larvae, and $s$ is the number of segments in P. aibuhitensis.

$$
S G R=\frac{\ln \left(\frac{\bar{S}_{n}}{\bar{S}_{n-1}}\right)}{T} \times 100 \%
$$

Where $\bar{S}_{n}$ and $\bar{S}_{(n-1)}$ are the average number of segments measured at the $\mathrm{n}^{\text {th }}$ and $(\mathrm{n}-1)^{\text {th }}$ month, respectively, and the $T$ (d) is the sampling interval in days.

\section{Data Processing}

The data were analyzed by SPSS 23.0 statistical analysis software, and one-way analysis of variance (ANOVA) was used to compare the organic matter content in sediments. Twoway ANOVA was used to compare the effects of sediment type and sampling time on the specific growth rate, density, and larvae mortality. Significant ANOVAs were followed by a LSD's multiple comparison. Differences were statistically significant if $p<0.05$.

\section{RESULTS}

\section{Organic Matter Content in Sediment}

The organic matter content between surface and deep layers of the sediment in all types of sediment was significantly different $(p<0.05$, Figure 2). Moreover, the organic matter content in the sediments increased in turn from $1 \#$ to $6 \#$, which was in line with the experimental design's expectation. The average organic matter content of sediment from $1 \#$ to 6 \# were 2.19, 2.30, 2.86, $3.25,3.51$, and $5.52 \%$, respectively.

\section{Specific Growth Rate}

Two-way ANOVA showed that the sampling time, the sediment type, and the interaction of the two factors have a significant impact on the specific growth rate (SGR) of the polychaete (time: $\mathrm{F}=14043, p<0.05$; type of sediment: $\mathrm{F}=6.045$, $p<0.05$; Interaction: $\mathrm{F}=67.277, p<0.05)$. There were significant differences in the three months' SGR under the same sediment $(p<0.05$, Figure 3$)$. The first month's SGR was significantly higher than that in the second and third months $(p<0.05)$. There was no significant difference in the same month's SGR among different sediments $(p>0.05)$.

\section{Density}

The results of two-way ANOVA showed that the sampling time had a significant effect on the density of larvae in different 


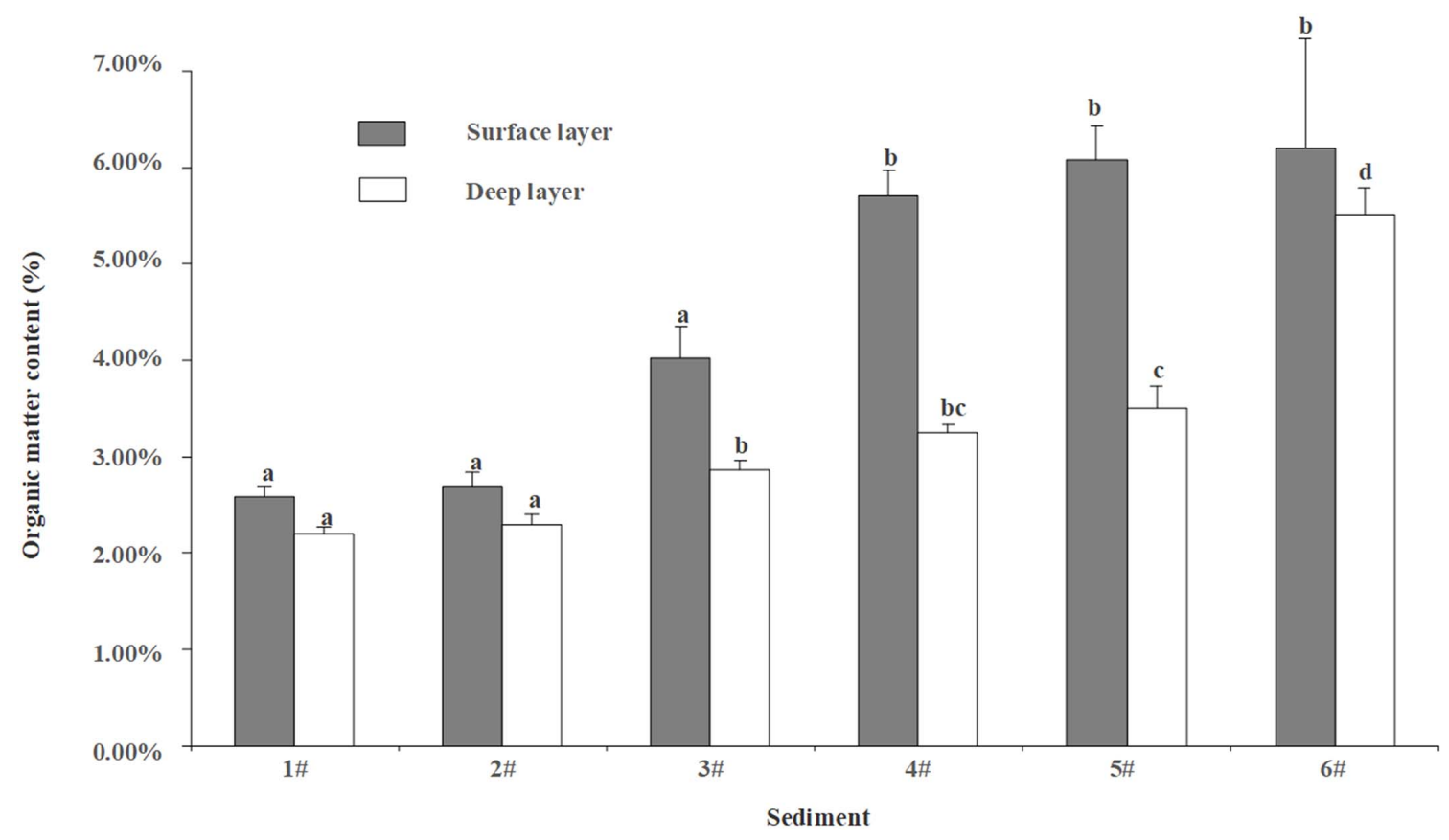

FIGURE 2 | Organic matter content of different sediments at surface layer (depth $=0-0.5 \mathrm{~cm}$ ) and deep layer (depth $\approx 5 \mathrm{~cm}$ ). Data with different letters were significantly different at the same layer. Error bars represent 1 SE.

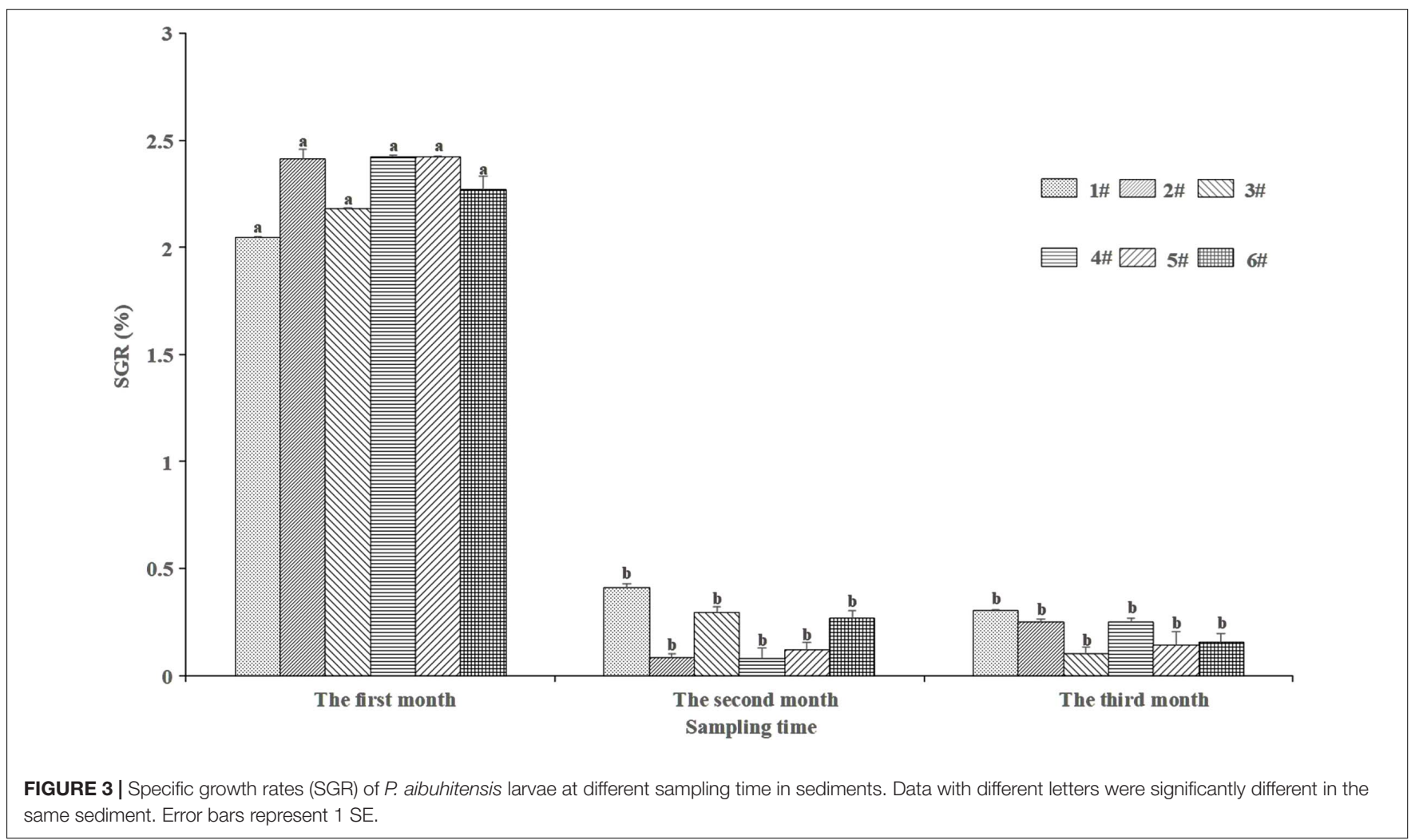

sediments $(\mathrm{F}=15.19, p<0.05)$, and the sediment had a significant effect on the density of larvae $(\mathrm{F}=2.897, p<0.05)$, but the interaction between them had no significant effect on the density of larvae $(\mathrm{F}=0.302, p>0.05)$. There was no significant difference in larval density among different sediments $(p>0.05$, Figure 4). The density of larvae increased with the sediment's 


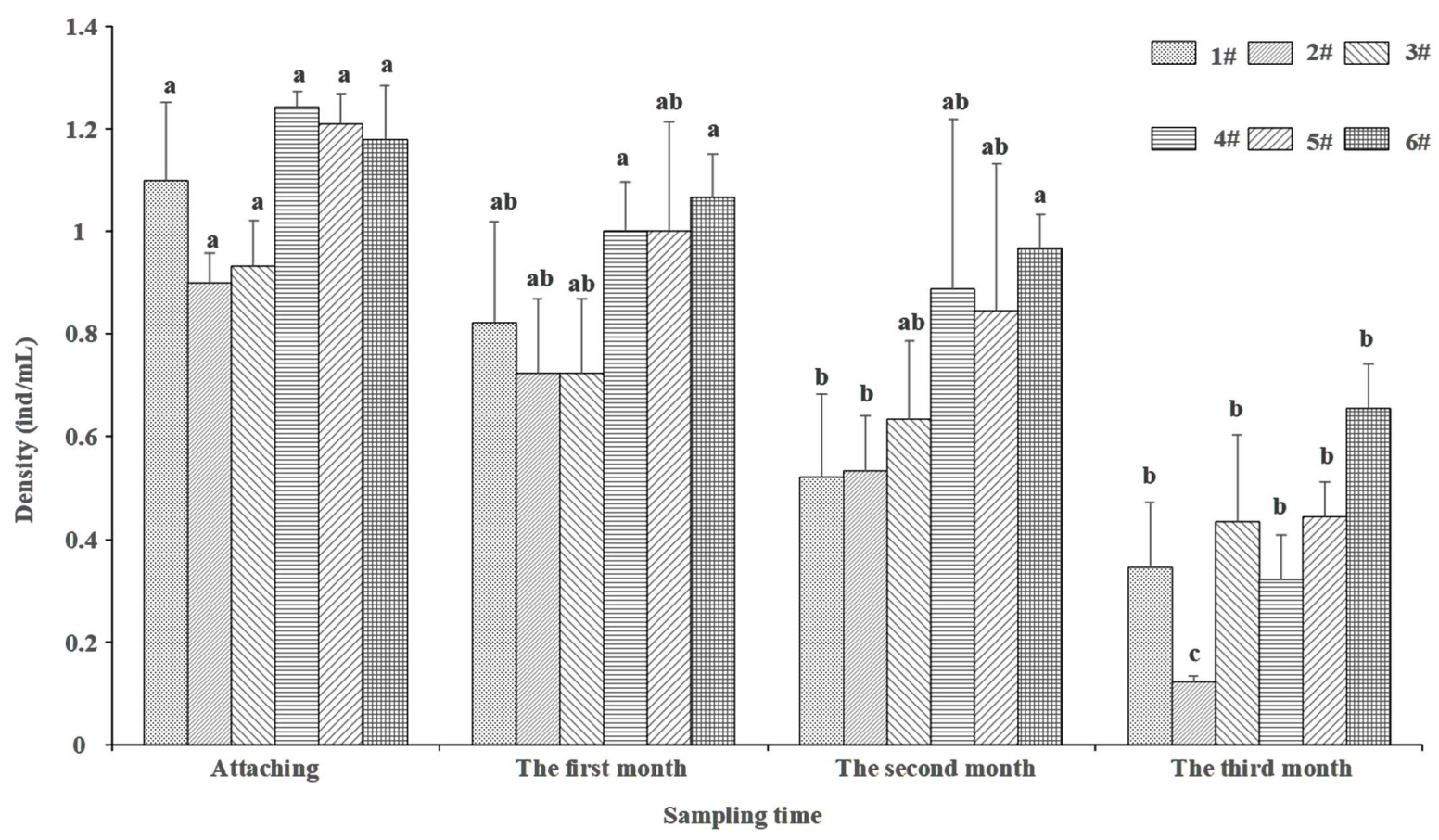

FIGURE 4 | Density of $P$. aibuhitensis larvae at different sampling time in different sediments. Data with different letters were significantly different in the same sediment. Error bars represent 1 SE.

organic matter content increase. Over time, the larvae density decreased gradually. There was a significant difference in larval density at different sampling times between sediment 1\#, 2\#, 4\#, and $6 \#(p<0.05)$, however, there was no significant difference in other sediments $(p>0.05)$.

\section{Mortality}

The results of two-way ANOVA showed larval mortality not changed through time $(\mathrm{F}=0.075, p>0.05)$, independent of type of sediment $(\mathrm{F}=0.073, p>0.05)$. The interaction between sediment type and sampling time had no significant effect on larval mortality $(\mathrm{F}=0.440, p>0.05)$. No statistically significant differences in mortality were observed among sediments when sampled at the same time point ( $p>0.05$, Figure 5). The average mortality of larvae was decreasing with the increasing organic content in sediments.

\section{DISCUSSION}

The density of polychaetes in habitat is positively correlated with the sediment's reworking (Duport et al., 2006). The various densities of polychaetes in different regions during the adult stage may be determined at the larval stage's attachment. $P$. aibuhitensis start to feed on monocytic algae when they develop to nectochaeta larvae with three chaetigerous segments (Liu et al., 2005) developed the fourth chaetigerous segment colonize the sediments. In the present study, the density of the $P$. aibuhitensis larvae had no significant difference among different sediment treatments with different organic matter contents at the initial attachment $(p>0.05)$. It was showed that the $P$. aibuhitensis larvae did not actively make a significant selection on sediments with different organic matter content during the initial attachment stage. However, previous studies found that deposit feeders, including $P$. aibuhitensis, were more inclined to choose higher-energy particles for ingestion (Hylleberg, 1975; Kihslinger and Woodin, 2000; Fang et al., 2018). Concomitantly, the organic matter contents preference in different sediment were significantly different in this study $(p<0.05)$. Fang et al. (2018) found a threshold of organic carbon content in sediment that decided $P$. aibuhitensis feeding on sediments. The organic content in sediment was about $2.12 \%$, which was enough for the feeding selection of polychaete (Fang et al., 2018). The sediment from the polychaete habitat usually had an organic content higher than 2.2\% (Fang et al., 2017), a reference for the present study's design. The experimental treatments' sediment differed significantly in organic matter (all higher than 2.19\%). It means that the sediments of the present study could supply enough food to the polychaete larvae. Therefore, in the present study, the $P$. aibuhitensis larvae showed non-selectivity for the sediment with different organic matters, not as the adult $P$. aibuhitensis, which might be due to the organic matter contents of all experimental treatments exceeding the maximum selection threshold of $P$. aibuhitensis larvae. Moreover, polychaetes have an excellent adaption to feeding sediments. Wang and Zhang (1998) showed that the highest feeding rate of Neanthes japonica to sediments was conducted under a food-poor environment, which illustrated 


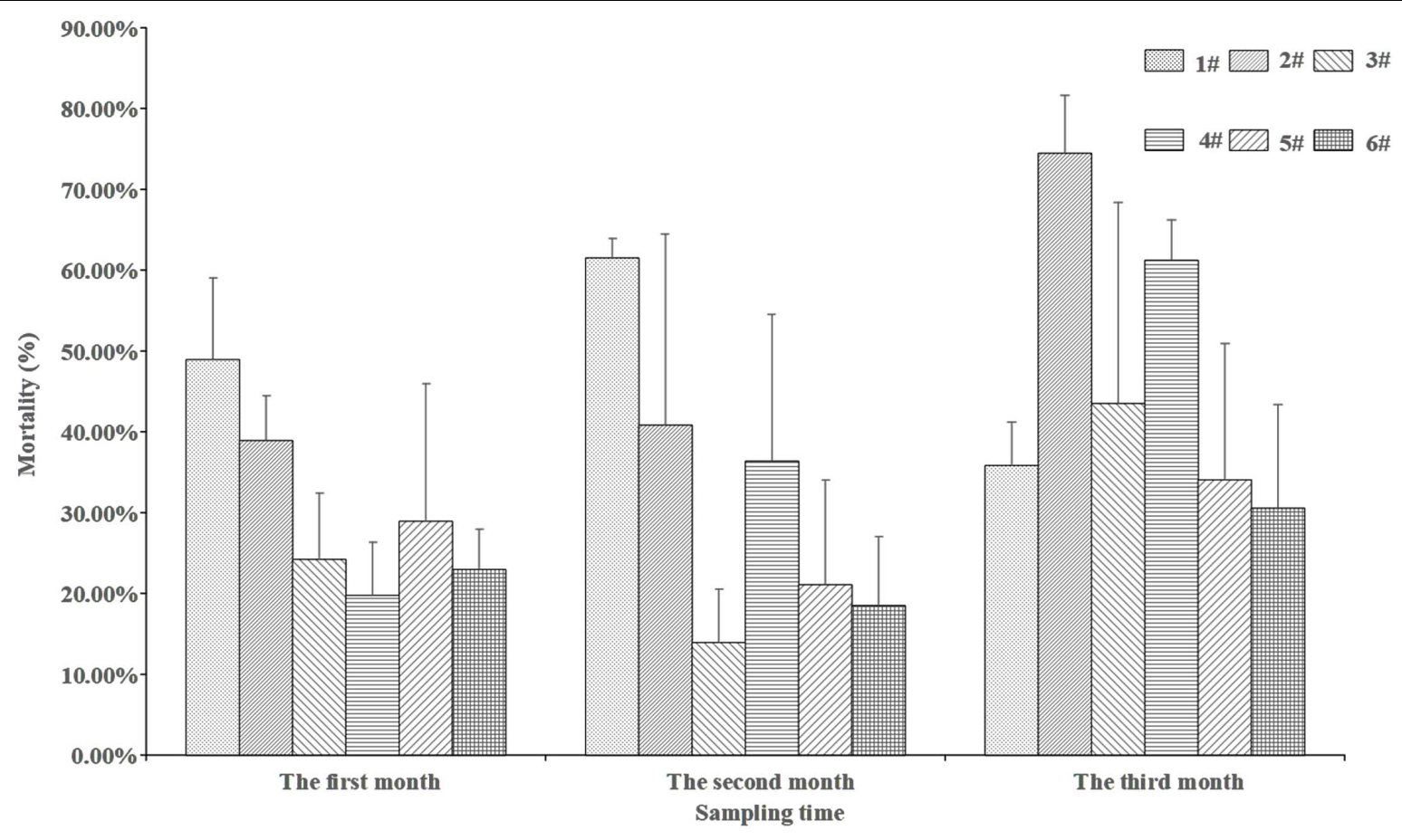

FIGURE 5 | Mortality of $P$. aibuhitensis larvae in different sampling time in different sediments. Error bars represent 1 SE.

that the instinct for feeding and survival of polychaete would be strengthened if the organic matter content was generally low in their habitats. However, environmental conditions in sediments were complicated. The organic matter content and other factors such as the size of the deposit particles (Wang and Zhang, 1998) and the hydrogen sulfide content (Li, 2014) might play important roles in affecting the selection of polychaetes to the sediment. Even if there were some other potential factors, the $P$. aibuhitensis larvae still showed non-selectivity to the sediment with different organic matter content. Passive selection by the environment might make different distributions at the habitat of $P$. aibuhitensis.

$P$. aibuhitensis Larvae will lose its ciliary, step into the creeping stage and begin to feed on the sediment to meet the needs of growth and development after the fourth pair of chaetigerous segments. After that, the larvae preferentially develop functional organs such as sensation, feeding, and swimming, which will benefit survival and proliferation. However, after this period, these organs' growth rate will be significantly slowed down, showing allometric growth patterns (Peter, 1986; Niklas, 1994). In this study, the specific growth rate of larvae in the first month was significantly higher than that of the second and third months $(p<0.05)$, and there was no significant difference in the specific growth rate of the second and third months, which indicated that the $P$. aibuhitensis larvae grew faster during the early period, and then grew slowly. This result was consistent with the allometric growth patterns.

Shi and Zhao (1993) showed that the growth and survival of the $P$. aibuhitensis larvae would decrease if larvae lived in a high density. A $0.35 \mathrm{ind} / \mathrm{cm}^{2}$ would be a good density for the growth and survival of larvae. According to the present results, the larvae's density in the initial attachment and first two months was much higher than $0.35 \mathrm{ind} / \mathrm{cm}^{2}$. The larvae density was $0.12-0.65 \mathrm{ind} / \mathrm{cm}^{2}$ in the third month and compared to the initial attachment density of $0.80-1.34$ ind $/ \mathrm{cm}^{2}$, indicating that many larvae died in the early stage. $\mathrm{Li}$ (2014) found that the content of sulfide in sediments increased with time. The sulfide content should be higher in sediment with higher organic matter such as $5 \#$ and $6 \#$ sediment. The $P$. aibuhitensis had a high tolerance for sulfide (Wang et al., 2017). However, the mortality of $P$. aibuhitensis larvae was lower in groups with higher organic matter. Especially in the third month, the density increased with the increasing organic matter content. Hence the sulfide could not be the critical factor for the induced mortality. Only natural habitat and kelp powder were present in the sediment; thus, no additional toxic matter influenced the results. On the contrary, the sediment with high organic matter could provide more food for the larvae, which would support the higher biomass of P. aibuhitensis larvae (Hylleberg, 1975; Kihslinger and Woodin, 2000; Fang et al., 2018). Therefore, the food limitation in the sediment might be the critical factor in the survival of $P$. aibuhitensis larvae.

\section{DATA AVAILABILITY STATEMENT}

The original contributions presented in the study are included in the article/supplementary material, further inquiries can be directed to the corresponding author/s. 


\section{AUTHOR CONTRIBUTIONS}

JinF, ZJ, and JiaF conceptualized the study. SM was responsible for the experimental operation. JinF, WH, and SM were in charge of the field sampling. SM conducted the sample determination. $\mathrm{WH}$ prepared and wrote the original draft. JinF, WH, and BL reviewed, edited, and wrote the manuscript. All authors read and approved the final manuscript.

\section{REFERENCES}

Chouikh, N., Gillet, P., Langston, W. J., Cheggour, M., Maarouf, A., and Mouabad, A. (2020). Spatial distribution and structure of benthic polychaete communities of Essaouira intertidal rocky shores (Atlantic coast of Morocco). J. Oceanol. Limnol. 38, 143-155. doi: 10.1007/s00343-019-8286-7

Duport, E., Gilbert, F., Poggiale, J. C., Dedieu, K., Rabouille, C., and Stora, G. (2007). Benthic macrofauna and sediment reworking quantification in contrasted environments in the Thau lagoon. Estuar. Coast. Shelf Sci. 72, 522-533. doi: 10.1016/j.ecss.2006.11.018

Duport, E., Stora, G., Tremblay, P., and Gilbert, F. (2006). Effects of population density on the sediment mixing induced by the gallery-diffusor Hediste (Nereis) diversicolor O.F. Müller, 1776. J. Exp. Mar. Biol. Ecol. 336, 33-41. doi: 10.1016/ j.jembe.2006.04.005

Fang, J., Jiang, Z., Fang, J., Kang, B., Gao, Y., and Du, M. (2018). Selectivity of Perinereis aibuhitensis (Polychaeta, Nereididae) feeding on sediment. Mar. Biol. Res. 14, 478-483. doi: 10.1080/17451000.2018.1426864

Fang, J., Wang, H., Fang, J., Jiang, Z., Du, M., Gao, Y., et al. (2017). The characteristics of the sedimentary environment in a typical habitat of Pernereis aibuhitensis Grube. Prog. Fis. Sci. 38, 1-8. doi: 10.11758/yykxjz.201608 01001

Gopal, A., Abdul Jaleel, K. U., Parameswaran, U. V., Sanjeevan, V. N., Saramma, A. V., Vijayan, A., et al. (2020). Distinctive community patterns with exceptional diversity of polychaetes around a tectonically active archipelago in the tropical Indian Ocean. Front. Mar. Sci. 7:710. doi: 10.3389/fmars.2020. 00710

Heilskov, A. C., and Holmer, M. (2001). Effects of benthic fauna on organic matter mineralization in fish-farm sediments: importance of size and abundance. ICES J. Mar. Sci. 58, 427-434. doi: 10.1006/jmsc.2000.1026

Hu, F., Sun, M., Fang, J., Wang, G., Li, L., Gao, F., et al. (2020). Carbon and nitrogen budget in fish-polychaete integrated aquaculture system. J. Oceanol. Limnol. doi: 10.1007/s00343-020-0218-z

Hylleberg, J. (1975). Selective feeding by Abarenicola pacifica with notes on Abarenicola vagabunda and a concept of gardening in lugworms. Ophelia 14, 113-137. doi: 10.1080/00785236.1975.10421972

Kihslinger, R. L., and Woodin, S. A. (2000). Food patches and a surface deposit feeding spionid polychaete. Mar. Ecol. Prog. Ser. 201, 233-239. doi: 10.3354/ meps 201233

Koo, B. J., and Seo, J. (2017). Sediment reworking by a polychaete, Perinereis aibuhitensis, in the intertidal sediments of the Gomso Bay, Korea. Ocean Sci. J. 3, 1-8. doi: 10.1007/s12601-017-0037-0

\section{FUNDING}

This study was funded by the National Natural Science Foundation of China (41876185), the Young Taishan Scholars Program of Shandong Province (tsqn201909166), Central Publicinterest Scientific Institution Basal Research Fund, CAFS (2020TD50), and China Agriculture Research System of MOF and MARA.

Li, D. (2014). The Effects of Different Environmental Conditions on the Larval Development of Perinereis aibuhitensis. Ph.D. Dissertation. Qingdao: Ocean University of China.

Li, S., Ren, Z., and Wang, T. (2017). Ecological characteristics of macrobenthos at the Yellow River estuary in summer. Prog. Fis. Sci. 38, 9-17. doi: 10.11758/ yykxjz.20160711001

Liu, M., Jiang, X., and Zhang, Y. (2005). Study on the embryonic and larval development of Perinereis aibuhitensis. Prog. Fis. Sci. 26, 13-17. doi: 10.3969/ j.issn.1000-7075.2005.02.003

Meng, S., Fang, J., Jiang, Z., Xu, Y., Dong, S., Yu, W., et al. (2020). Experimental study of the choice behavior of Perinereis aibuhitensis Grube among different sediment types. Prog. Fis. Sci. 41, 110-116. doi: 10.19663/j.issn2095-9869. 20190410004

Niklas, K. J. (1994). The Scaling of Form and Process. Chicago: University of Chicago Press, xvii, 395.

Peter, R. H. (1986). The Ecological Implications of Body Size, 2nd Edn. Cambridge: Cambridge University Press, 184-215.

Shi, X., and Zhao, Q. (1993). Effects of several ecological factors on early stagesurvival and growth of Perinereis aibuhitensis. Chinese J. Ecol. 12, 21-24.

Sun, R., and Yang, D. (2004). Fauna Sinica. Invertebrata 33. Annelida. Polychaeta II. Neridida. Beijing: Science Press, 180-183.

Wang, H., Wang, G., Fang, J., Jiang, Z., Du, M., Gao, Y., et al. (2017). Acute sulphide toxicity in Perinereis aibuhitensis under different salinities and temperatures: LC $_{50}$ and antioxidant responses. Aquat. Biol. 26, 75-85. doi: 10.3354/ab00674

Wang, S., and Zhang, Z. (1998). Study of Neanthes japonica feeding on natural sediment. J. Ocean Univ. Qingdao 28, 3-5. doi: 10.16441/j.cnki.hdxb.1998. 04.012

Conflict of Interest: SM was employed by China Ocean Press.

The remaining authors declare that the research was conducted in the absence of any commercial or financial relationships that could be construed as a potential conflict of interest.

Copyright (C) 2021 Fang, He, Meng, Jiang, Fang, Mao and Liang. This is an openaccess article distributed under the terms of the Creative Commons Attribution License (CC BY). The use, distribution or reproduction in other forums is permitted, provided the original author(s) and the copyright owner(s) are credited and that the original publication in this journal is cited, in accordance with accepted academic practice. No use, distribution or reproduction is permitted which does not comply with these terms. 